\title{
Modified Theory of Constraints Heuristics(MTOCh1) Keeping Complete Shipment as Constraint
}

\author{
Ajay Gupta \\ Department of Industrial \& Production Engineering, National Institute of Technology Jalandhar, India
}

Copyright $(2016$ by authors, all rights reserved. Authors agree that this article remains permanently open access under the terms of the Creative Commons Attribution License 4.0 International License

\begin{abstract}
Fox gave the theory of constraints heuristics (TOCh) to determine the optimal product mix. This algorithm was modified by Lea for multiple constraint situations. Neither of these heuristics is applicable in the situations where complete shipment is an additional constraint. In this paper, some modifications are suggested in TOCh. With these modifications, the heuristics can be used in the complete shipment constraint situations. The working of the modified heuristics has been explained by taking two numerical examples. By comparing the results obtained from this heuristics with those obtained from integer linear programming model, it has been proved that the model gives satisfactory results.
\end{abstract}

Keywords Theory of Constraints, Theory of Constraints heuristics (TOCh), Integer Linear Programming Model

\section{Introduction}

A product mix problem arises when the total demand placed on a system is more than the ability of the system to meet it. There are many methods available to solve the product mix problems like linear programming, genetic algorithm, Tabu search-simulated annealing etc. Theory of constraints (TOC) has been emerging as a powerful management philosophy over the past 35 years. Initial applications of TOC were in the area of operations management. Fox [1987] tried to expand the application of TOC to product mix problems and gave Theory of constraints heuristics (TOCh) which can be used to determine the optimal product mix. Lee \& Plenert [1993], in their paper, explained the steps in TOCh. Plenert [1993], from his work, showed that TOCh gives the optimal solution, if there is only one constraint. But it yields either sub-optimal solution or infeasible solution, if there are multiple constraints. Mishra et al. [2005] developed a hybrid Tabu Search- Simulated Annealing model to solve product mix problem and by taking an illustrative example, concluded that the hybrid Tabu- simulated annealing model yields better results than both TOC heuristics and integer linear programming. Similarly, Kee \& Schmidt [2000] concluded that TOC model generates more profits, if management has no control over labour and overhead expenses, while Activity Based Costing ( $\mathrm{ABC}$ ) generates higher profits if the management has complete control over the labour and overhead expenses. Spoede et al. [1994] using numerical examples proved that throughput accounting outperforms ABC in product mix decisions. The findings of Kee [1995] are contrary to it. To overcome the limitations of TOCh proposed by Fox [1987], Fredendall \& Lea [1997] proposed a Revised Theory of constraints heuristics (RTOCh) for multi-constraint situations and compared the outcome of their proposed heuristics with the solution generated by integer linear programming. Luebbe \& Finch [1992] concluded from their analysis that TOC and linear programming yield similar results. Most of these researchers seem to converge to the view that TOCh performs at par or poorer than integer linear programming as far as the problem of determining the product mix is concerned. None of the authors could appreciate the fact that TOC goes beyond the point of just determining product mix. It helps in prioritizing the order of manufacturing these products, which linear programming does not. Plenert agrees that presence of contingencies complicate the solution process and makes it difficult to achieve the targeted output, but he failed to appreciate the fact the wrong sequencing of jobs can further deteriorate the performance. TOCh helps us in avoiding the wrong sequencing.

According to $\mathrm{TOCh}$, the products are to be manufactured in the order of decreasing ratio $(\mathrm{R})$ of their throughput to the constraint time utilization. By doing so, the contingency, if any, will effect the least profitable products only. So, the gap between planned throughput and the actual throughput will be the minimum. Though the capacity utilization of various resources for the product mix suggested by integer linear programming (ILP) can be calculated and from these capacity utilization values, constraint can be identified. But ILP by itself does not stress the need for identification of constraint and strict monitoring of its output while TOC highlights this need and suggests the methods like Drum 
Buffer Rope (DBR) to protect the throughput of Capacity Constrained Resource (CCR). Thus comparing the solution obtained from TOCh in isolation with ILP can be misleading. TOC heuristic is a part of TOC philosophy. TOC philosophy provides a complete production management and control methodology. It is better to arrive at a near optimal solution and achieve it rather than arriving at a perfectly optimal solution and missing it by a large margin. Last but not the least, TOCh is simple to apply, which is not the case with integer linear programming or other complex algorithms.

For determining the product mix, the demand of various products from different customers/distributors is aggregated and this aggregated demand is used in product mix problems. While arriving at product mix solutions, it is assumed that a customer can be supplied with partial shipments, but this is not the case in many situations. A visit to a number of companies in the local region confirmed this fact. Jalandhar is a hub of hand tool industries. Companies of this region supply hand tools to the customers in various parts of the world. To find their method of production planning, we visited many hand tool- manufacturing units of the region. From the survey, it was found that these companies have negligible set up change over time particularly for the operations after forging. So, they manufacture the products order by order, particularly on the operations like broaching, grinding, polishing, shot blasting, electroplating and packing etc. Also the international customers do not accept partial shipments. None of the researchers have worked on modifications needed in TOCh to make it applicable under such situations. So, the objective of the present paper is to propose a modified TOCh for the situations where partial shipments are not permitted and to test the working of proposed heuristics by comparing the results obtained from the proposed heuristic with the results obtained from integer linear programming model. To start with, the conventional TOCh, as proposed by Fox is presented below

\section{TOC Heuristics}

TOCh heuristics proposed by Fox involves the following steps to determine the product mix to be manufactured

1. Calculate the capacity of each resource

2. Calculate the load on each resource

3. Determine the critically constraint resource (CCR)

4. Calculate the throughput per unit for each product

5. Calculate the throughput per unit constraint time (r) for each product

6. Determine how much of each product should be produced. For this purpose, first allocate the CCR capacity to manufacture the product with highest ratio $r$ then to next higher ratio and so on till the capacity of CCR is fully exhausted. This determines the product mix to be manufactured.

\section{Modified TOC Heuristics, when Complete Shipment is a Constraint}

Based on the logic given by Fox, it has been proposed that the throughput per constraint minute for each distributor (customer) order should be used to prioritize the pending orders. The steps involved in the proposed heuristics are given in this Section. To start with some notations used in the steps are defined.

Notations Used

i denotes distributors ( for various distributors $\mathrm{i}=$ $1,2,3 \ldots . \mathrm{m})$

$\mathrm{j}$ denotes products (for various products $\mathrm{j}=1,2,3 \ldots \ldots \mathrm{n}$ )

$\mathrm{k}$ denotes resources used in production (for various resources, $\mathrm{k}=1,2,3 \ldots \ldots . \mathrm{p}$ )

$\mathrm{Th}_{\mathrm{j}}$ denotes throughput per unit product $\mathrm{j}$

$D_{i j}$ denotes demand of distributor $i$ for product $j$

$x_{i}$ denotes a binary variable $\left(x_{i}=1\right.$, if the demand of distributor $i$ is met, 0 otherwise)

$t_{k j}$ denotes time to process one unit of product $j$ on the resource $\mathrm{k}$

$\mathrm{Q}_{\mathrm{k}}$ Maximum time available on resource $\mathrm{k}$

$\mathrm{b}$ denotes the bottleneck resource

$t_{b j}$ denotes time to process one unit of product $j$ on the bottleneck resource $b$.

$\mathrm{R}_{\mathrm{i}}$ denotes the throughput to the constraint time ratio for customer i

$\operatorname{dif}_{\mathrm{k}}$ denotes the difference between the capacity of a resource $\mathrm{k}$ and its load

MPS denotes set of customers in the master production schedule of the next planning period

NPS denotes set of customers not included in the master production schedule of the next planning period $t_{b \text {,left }}$ denotes the unallocated time left on the bottleneck $b$ $\mathrm{m}$ denotes the total number of customers whose have placed the orders for next planning period

$\mathrm{x}$ denotes the number of customers in the master production schedule (MPS)

$\mathrm{m}$-x denotes the number of customers in the set NPS

Steps in the Proposed Modified Theory of Constraints Heuristics ( MTOCh1)

1. Determine the capacity $\left(\mathrm{Q}_{\mathrm{k}}\right)$ of each resource $\mathrm{k}$

2. Calculate the load on each resource.

$$
\text { Load on the resource } k=\sum_{j=1}^{n} t_{k j}\left(\sum_{i=1}^{m} D_{i j}\right)
$$

For various resources, $\mathrm{k}=1,2, \ldots . \mathrm{p}$

3. Determine the critically constraint resource (CCR). For this purpose, calculate the difference $\left(\mathrm{dif}_{\mathrm{k}}\right)$ between the capacity and load on each resource by using the following equation 


$$
\operatorname{dif}_{\mathrm{k}}=\mathrm{Q}_{\mathrm{k}}-\sum_{\mathrm{j}=1}^{\mathrm{n}} \mathrm{t}_{\mathrm{kj}}\left(\sum_{\mathrm{i}=1}^{\mathrm{m}} \mathrm{D}_{\mathrm{ij}}\right)
$$

The resource for which $\operatorname{dif}_{\mathrm{k}}<0$ is the bottleneck resource. In this case, we are assuming that we have only one bottleneck resource $b$

4. Calculate the throughput for each customer order, by using the following formula

Throughput for the customer $\mathrm{i}=\sum_{\mathrm{j}=1}^{\mathrm{n}} \mathrm{d}_{\mathrm{ij}} \cdot \mathrm{Th}_{\mathrm{j}}$

5. Calculate the constraint time required to manufacture each customer order, by using the following formula

Bottleneck time consumption for the customer i

$$
=\sum_{j=1}^{n} d_{i j} \cdot t_{b j}
$$

6. Calculate the throughput to the constraint time ratio

(Ri) for each customer, as given below

Throughput per unit constraint minute for the

$$
\text { customer } \mathrm{i}=\frac{\sum_{\mathrm{j}=1}^{\mathrm{n}} \mathrm{d}_{\mathrm{ij}} \cdot \mathrm{Th}_{\mathrm{j}}}{\sum_{\mathrm{j}=1}^{\mathrm{n}} \mathrm{d}_{\mathrm{ij}} \cdot \mathrm{t}_{\mathrm{bj}}}
$$

7. Arrange the customers in the descending order of this ratio

8. First allocate the CCR capacity to manufacture the products needed to meet the requirement of the customer with highest ratio in step seven, then to next higher ratio and so on till the capacity of CCR is fully exhausted or the time left on constraint is not sufficient to meet the requirement of next customer in the list. This will divide the customers in two sets i.e. the customers included in the master production schedule (MPS) and those not included in the master production schedule (NPS)*

*When the solution obtained using the above eight steps was compared with the solution obtained from integer linear programming, it was found that in some of the situations the solution was inferior. So, after careful analysis, the following step was added to it.

9. Steps to check/make the solution optimal (optimality test)

a. Arrange the customers in the NPS set in the descending order of their throughput and let us call them NPS $1, \mathrm{NPS}_{2}$

b. Take the first customer $\left(\mathrm{NPS}_{1}\right)$ from the NPS set

c. Determine the candidates from the set MPS that can be replaced by $\mathrm{NPS}_{1}$. These candidates must satisfy the following conditions ii

Their throughput should be less than the throughput of NPS

Summation of their processing time on constraint and the unutilized time on the constraint should be more than the processing time of $\mathrm{NPS}_{1}$ on the constraint.

d. From the list of such candidates, take the candidate with minimum throughput. Move this candidate to the end of NPS set and NPS1 to MPS set.

e. Repeat the steps $\mathrm{c}$ and $\mathrm{d}$ for all the candidates in the NPS set

This determines the optimal order mix for the MPS.

Note: If at any stage, while comparing a customer in the set NPS with the customers in the set MPS, there is no candidate in the MPS set that meets the conditions $i$ and ii, then the solution is optimal and the further iterations stop.

\section{Testing of Proposed Heuristic (Mtoch1)}

The working of the proposed heuristic has been tested by taking the following two illustrative scenarios. Both the scenarios have been taken from Plenert's paper. The scenarios have been modified a bit to make them applicable to the current situation.

\section{Scenario 1}

The first scenario involves a company producing two products $\mathrm{P}$ and $\mathrm{Q}$. Product $\mathrm{P}$ is assembled from part 1 and 2 made from raw materials 1(RM1) and 2(RM2) respectively and a purchased part costing $\$ 5$ per unit. While the product $\mathrm{Q}$ is assembled from part 2(RM2) and 3(RM3) made from raw materials 2 and 3 respectively. The unit cost of raw material 1,2 and 3 is $\$ 20$ each. Per unit selling price of products $\mathrm{P}$ and $\mathrm{Q}$ are $\$ 90$ and 100 respectively. The manufacturing sequence of these products along with the processing timings is given in the Fig. 1.

From the Fig.1, total aggregated demand is 100 units of $\mathrm{P}$ and 50 units of $Q$. This demand of 100 and 50 units of $P$ and $Q$ respectively has been arbitrarily broken into the demand of five distributors and is given in Table 1

Table 1. Breakup of Demand Among Distributors

\begin{tabular}{|c|c|c|}
\hline Distributor & Product P & Product Q \\
\hline 1 & 25 & 5 \\
\hline 2 & 30 & 20 \\
\hline 3 & 15 & 15 \\
\hline 4 & 20 & 10 \\
\hline 5 & 10 & 0 \\
\hline Total demand & 100 & 50 \\
\hline
\end{tabular}




\section{Product $\mathrm{P}$}

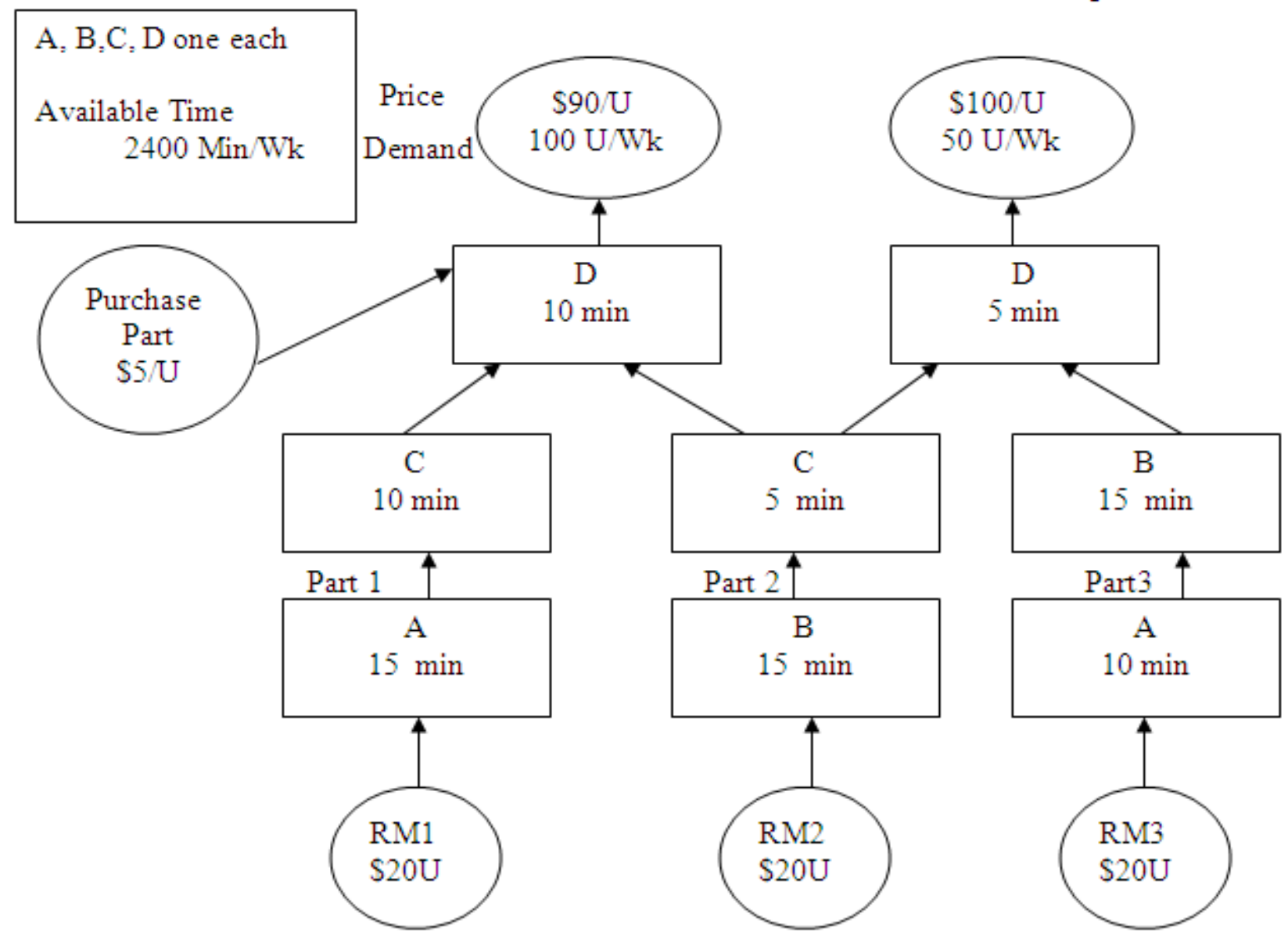

Figure 1. Steps for Manufacturing Products $\mathrm{P}$ and $\mathrm{Q}$

From the data given, Throughput per unit of products $\mathrm{P}$ and Q come out to be $\$ 45(90-20-20-5)$ and $\$ 60$ (100-20-20) respectively.

From the Fig. 1, the unit processing timings have been calculated for both the products in each of the four departments and are given in $2^{\text {nd }}$ and $3^{\text {rd }}$ columns of Table 2. Next step is to calculate total load on each department, for illustration

Total load for department $\mathrm{A}=15 * 100+10 * 50=2000$ minutes/week.

Similarly, the total loads on the departments B, C and D have been calculated. This information, along with the capacity of each department is summarized in $4^{\text {th }}$ and $5^{\text {th }}$ columns of Table 2 .

Table 2. Unit Processing Time of Various Products, capacity, load of Different Departments

\begin{tabular}{|c|c|c|c|c|}
\hline \multirow{2}{*}{ Department } & \multicolumn{2}{|c|}{ Processing time/unit } & \multirow{2}{*}{ Capacity } & \multirow{2}{*}{ Load } \\
\cline { 2 - 3 } & Product P & Product Q & & \\
\hline A & 15 & 10 & 2400 & 2000 \\
\hline B & 15 & 30 & 2400 & $3000^{*}$ \\
\hline C & 15 & 5 & 2400 & 1750 \\
\hline D & 10 & 5 & 2400 & 1250 \\
\hline
\end{tabular}

*Capacity constraint resource
From the values given in the Table 2, total load on the department $B$ is more than the processing time available per week. So, department B is the constraint in this situation.

Next step is to calculate throughput per distributor order $\left(\sum_{\mathrm{j}=1}^{\mathrm{n}} \mathrm{d}_{\mathrm{ij}} . \mathrm{Th}_{\mathrm{j}}\right)$ and the constraint time needed to meet the order of each distributor $\left(\sum_{j=1}^{n} d_{i j} \cdot t_{b j}\right)$.

e. $g$ the total throughput from meeting the order of distributor 1 is

$$
45 * 25+60 * 5=\$ 1425
$$

and the constraint time utilized in meeting this demand is

$$
25 * 15+30 * 5=525 \mathrm{~min}
$$

Therefore, the throughput per constraint minute ratio $\left(\mathrm{R}_{\mathrm{i}}\right)$ for distributor 1

$$
=1425 / 525=2.71
$$

Same method was used to calculate throughput per constraint minute for each distributors. After calculating the ratio $\left(\mathrm{R}_{\mathrm{i}}\right)$, distributors were arranged in the descending order of throughput per constraint minute ratio $\left(\mathrm{R}_{\mathrm{i}}\right)$ as shown in the Table 3. This Table shows the order of adding the distributors in the list of scheduled orders (master production schedule), cumulative constraint load and the constraint time left after addition of each distributor. 
Table 3. Addition of Distributors to MPS Set

\begin{tabular}{|c|c|c|c|c|c|c|}
\hline Distributor & Throughput (\$) & $\begin{array}{c}\text { Constraint } \\
\text { time used (min) }\end{array}$ & $\begin{array}{c}\text { Throughput } \\
\text { per constraint minute }\left(\mathrm{R}_{\mathrm{i}}\right)\end{array}$ & $\begin{array}{c}\text { Cumulative } \\
\text { constraint time used ( } \mathrm{min})\end{array}$ & $\begin{array}{c}\text { Constraint time } \\
\text { left (min) }\end{array}$ & $\begin{array}{c}\text { Cumulative } \\
\text { Throughput }(\$)\end{array}$ \\
\hline 5 & 450 & 150 & 3 & 150 & 2250 & 450 \\
\hline 1 & 1425 & 525 & 2.71 & 675 & 1725 & 1875 \\
\hline 4 & 1500 & 600 & 2.5 & 1275 & 1125 & 3375 \\
\hline 2 & 2550 & 1050 & 2.43 & 2325 & 75 & 5925 \\
\hline \multicolumn{6}{|c|}{ Total } & 5925 \\
\hline
\end{tabular}

As per the steps of modified TOCh, demands of the distributors $5,1,4$ and 2 can be fully met. Throughput was calculated for this solution and comes out to be $\$ 5925$.

Let us apply step 9 of modified TOCh proposed and explore the possibility of including distributor 3 and check if by doing so, the overall profitability can be improved.

Distributor 3 needs 675 minutes of constraint timing, out of which 75 minutes (unutilized time) are available with department 2 (constraint) so, it can replace one of those distributors whose constraint time usage is $(675-75) 600$ minutes or more and whose throughput is less than that of distributor 3. Constraint time used by distributors $2 \& 4$ is more than or equal to 600 minutes but the throughput of only distributor 4 is less than that of distributor 3 . Let us replace distributor 4 with distributor 3 in the MPS set and put the distributor 3 at the end of the priority list in the MPS set. The improved TOC solution given Table 4

Table 4. Solution after Iteration

\begin{tabular}{|c|c|c|c|c|c|}
\hline Rank & Distributor & $\begin{array}{c}\text { Constraint } \\
\text { time used } \\
(\mathrm{min})\end{array}$ & $\begin{array}{c}\text { Cumulative } \\
\text { constraint } \\
\text { time used } \\
(\mathrm{min})\end{array}$ & $\begin{array}{c}\text { Constraint } \\
\text { time } \\
\text { left (min) }\end{array}$ & $\begin{array}{c}\text { Throughput } \\
(\$)\end{array}$ \\
\hline 1 & 5 & 150 & 150 & 2250 & 450 \\
\hline 2 & 1 & 525 & 675 & 1725 & 1425 \\
\hline 4 & 2 & 1050 & 1725 & 675 & 2550 \\
\hline 5 & 3 & 675 & 2400 & 0 & 1575 \\
\hline 3 & $4 *$ & 600 & 3000 & & \\
\hline \multicolumn{7}{|c|}{ Total } \\
\hline
\end{tabular}

* Demand of this distributor cannot be met

Although the throughput of distributor 4 is more than the throughput of distributors 1 and 5 but they use lesser time of constraint than needed to process the order of distributor 4 . So distributor 4 cannot replace any other distributor in MPS set and according to the proposed heuristics, the solution obtained is optimal. Demands of the distributors 5, 1, 2 and 3 can be fully met. Throughput calculated for this solution comes out to be $\$ 6000$

To compare the results of the proposed heuristics, General integer linear programming model for such situations was constructed and is given below

$$
\operatorname{Max}(Z)=\sum_{i=1}^{m} x_{i} \sum_{j=1}^{n} d_{i j} T h_{j}
$$

Subject to the constraints

$$
\sum_{i=1}^{m} x_{i} \sum_{j=1}^{n} d_{i j} t_{k j} \leq Q_{k} \quad(\text { for } k=1,2 \ldots \ldots . p)
$$

Where $\mathrm{x}_{\mathrm{i}}$ are binary variables

Using the above model, formulation of the current scenario as an integer linear programming problem is

$\operatorname{Maximize}(Z)=1425 \mathrm{x}_{1}+2550 \mathrm{x}_{2}+1575 \mathrm{x}_{3}+1500 \mathrm{x}_{4}+450$

$$
\mathrm{x}_{5}
$$

Subject to the constraints

$425 \mathrm{x}_{1}+650 \mathrm{x}_{2}+375 \mathrm{x}_{3}+400 \mathrm{x}_{4}+150 \mathrm{x}_{5}$

$525 \mathrm{x}_{1}+1050 \mathrm{x}_{2}+675 \mathrm{x}_{3}+600 \mathrm{x}_{4}+150 \mathrm{x}_{5} \leq 2400$

$400 \mathrm{x}_{1}+550 \mathrm{x}_{2}+300 \mathrm{x}_{3}+350 \mathrm{x}_{4}+150 \mathrm{x}_{5} \leq 2400$

$275 \mathrm{x}_{1}+400 \mathrm{x}_{2}+225 \mathrm{x}_{3}+250 \mathrm{x}_{4}+100 \mathrm{x}_{5} \quad \leq 2400$

where $\mathrm{x}_{1}, \mathrm{x}_{2}, \mathrm{x}_{3}, \mathrm{x}_{4}, \mathrm{x}_{5}$ are binary variables.

Above problem was solved using integer linear programming tool in Excel solver and the results obtained are given in the Table 5

Putting these values of $\mathrm{x}_{1}, \mathrm{x}_{2} \ldots \ldots \ldots \mathrm{x}_{5}$. in the objective function equation, The optimal throughput comes out to be $\$ 6,000$

Table 5. Solution Obtained Using Integer Linear Programming

\begin{tabular}{|c|c|c|c|c|c|}
\hline Variable & $\mathrm{x}_{1}$ & $\mathrm{x}_{2}$ & $\mathrm{x}_{3}$ & $\mathrm{x}_{4}$ & $\mathrm{x}_{5}$ \\
\hline Value & 1 & 1 & 1 & 0 & 1 \\
\hline
\end{tabular}

This value is same as obtained from the proposed modified TOC heuristics (MTOCh1) for such situations. This shows that the proposed heuristics MTOCh1 generates the optimal solution.

To further validate the model, it was tested on a more complex problem given below

\section{Scenario 2}

The situation involves a company producing four products $\mathrm{R}, \mathrm{S}, \mathrm{T}$ and $\mathrm{U}$. Product $\mathrm{R}$ requires raw materials 1 and 2 , product $S$ requires raw materials 2 and 3 , product $T$ requires raw materials 4 and 5 while the product $U$ requires raw materials 5 and 6 respectively. The unit cost of raw materials $1,2,3,4,5$ and 6 are $\$ 5,10,5,10,10$ and 10 respectively. Per unit selling price of products $\mathrm{R}, \mathrm{S}, \mathrm{T}$ and $\mathrm{U}$ are $\$ 90, \$ 80, \$ 70$ and $\$ 60$ respectively. The manufacturing sequence of these products along with the processing timings are given in the Fig. 2. 


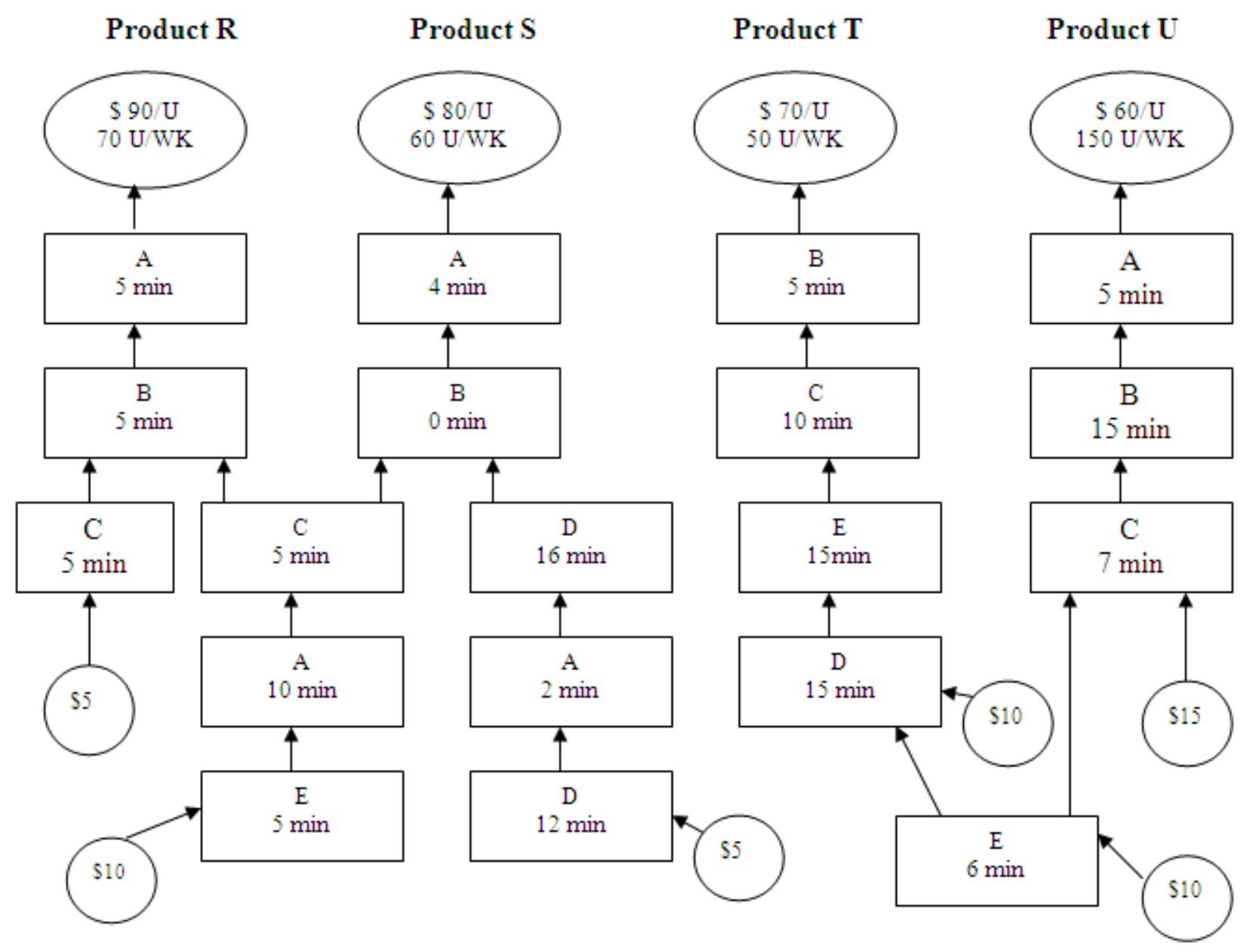

Figure 2. Steps for Manufacturing Products R,S,T and U

Table 6. Demand of Various Distributors

\begin{tabular}{|c|c|c|c|c|}
\hline \multirow{2}{*}{ Distributor } & \multicolumn{5}{|c|}{ Demand of Product } \\
\cline { 2 - 5 } & $\mathrm{R}$ & $\mathrm{S}$ & $\mathrm{T}$ & $\mathrm{U}$ \\
\hline 1 & 20 & 10 & 5 & 20 \\
\hline 2 & 10 & 15 & 5 & 20 \\
\hline 3 & 5 & 20 & 10 & 50 \\
\hline 4 & 15 & 10 & 15 & 30 \\
\hline 5 & 20 & 5 & 15 & 30 \\
\hline Total demand & 70 & 60 & 50 & 150 \\
\hline
\end{tabular}

The problem has been modified a bit and the gross requirements of various products have been divided into the requirement of five distributors shown in Table 6. This has been done to make it applicable to the current research issue of customer wise complete shipment constraint. Similarly, the processing time available on each machine has been increased to 2800 minutes so that it becomes a single constraint situation.

From the data given in the Fig. 2, Throughput per unit for products R,S,T and U comes out to be $\$ 75$ ( $90-10-5)$, $\$ 65$ (80-10-5), $\$ 50$ (70-10-10) and $\$ 35(60-10-15)$ respectively.
From the Fig. 2, the unit processing timings were calculated for each of the four products in each of the four departments and are given in Table 7. Next the total load on each department was calculated, for illustration

Total load for department $A=15 * 70+16 * 60+0 * 50+$ $5 * 150=2760$ minutes $/$ week.

Similarly, the loads were calculated for the departments B, $\mathrm{C}, \mathrm{D}$ and $\mathrm{E}$. This information is summarized in the Table 7.

As per the values given in the Table 7, total load on the department $\mathrm{B}$ is more than the processing time available per week. So, department B is the constraint in this situation.

Next step is to calculate throughput per distributor order and the constraint time needed to meet each distributor order. E.g. the total throughput of meeting the order of distributor 1 is

$$
75 * 20+65 * 10+50 * 5+35 * 20=\$ 3100
$$

and the constraint time needed to meet this demand is

$$
5 * 20+0 * 10+5 * 5+15 * 20=425 \min
$$

Therefore, the throughput per constraint minute for distributor $1=3100 / 425=7.29$ 
Table 7. Unit Processing Time of Various Products, capacity, load of Different Departments

\begin{tabular}{|c|c|c|c|c|c|c|}
\hline \multirow{2}{*}{ Department } & \multicolumn{4}{|c|}{ Processing time/unit (min) } & \multirow{2}{*}{$\begin{array}{c}\text { Capacity } \\
\text { (min/week) }\end{array}$} & \multirow{2}{*}{$\begin{array}{c}\text { Load } \\
(\mathrm{min} / \text { week })\end{array}$} \\
\hline & Product R & Product S & Product T & Product U & & \\
\hline A & 15 & 16 & 0 & 5 & 2800 & 2760 \\
\hline B & 5 & 0 & 5 & 15 & 2800 & $2850^{*}$ \\
\hline $\mathrm{C}$ & 10 & 5 & 10 & 7 & 2800 & 2550 \\
\hline $\mathrm{D}$ & 0 & 28 & 15 & 0 & 2800 & 2430 \\
\hline E & 5 & 5 & 21 & 6 & 2800 & 2600 \\
\hline
\end{tabular}

*Capacity constraint resource

Table 8. Addition of Distributor to MPS

\begin{tabular}{|c|c|c|c|c|c|c|c|}
\hline Rank & Distributor & Total Throughput(\$) & $\begin{array}{l}\text { Constraint } \\
\text { time used }\end{array}$ & $\begin{array}{c}\text { Throughput/ } \\
\text { constraint } \\
\text { minute }\end{array}$ & $\begin{array}{c}\text { Cumulative } \\
\text { constraint } \\
\text { time used }\end{array}$ & $\begin{array}{l}\text { Constraint } \\
\text { time left }\end{array}$ & $\begin{array}{c}\text { Cumulative } \\
\text { Throughput(\$) }\end{array}$ \\
\hline 1 & 1 & 3100 & 425 & 7.29 & 425 & 2375 & 3100 \\
\hline 2 & 2 & 2675 & 375 & 7.13 & 800 & 2000 & 5775 \\
\hline 3 & 4 & 3575 & 600 & 5.96 & 1400 & 1400 & 9350 \\
\hline 4 & 5 & 3625 & 625 & 5.8 & 2025 & 775 & 12,975 \\
\hline \multirow[t]{2}{*}{5} & $3^{*}$ & 3925 & 825 & 4.76 & & & \\
\hline & \multicolumn{6}{|c|}{ Total } & 12,975 \\
\hline
\end{tabular}

* Demand of this distributor cannot be met.

Same method was used to calculate throughput per constraint minute for each distributor. After calculating the ratio $\left(\mathrm{R}_{\mathrm{i}}\right)$, distributors were arranged in the descending order of throughput per constraint minute ratio $\left(\mathrm{R}_{\mathrm{i}}\right)$ as shown in the Table 8. This Table shows the order of adding the distributors in the list of scheduled orders (master production schedule), cumulative constraint load and the constraint time left after addition of each distributor.

Demands of the distributors 1, 2, 4 and 5 can be fully met. Throughput for this solution comes out to be $\$ 12,975$

Let us apply step 9 of modified TOCh proposed and explore the possibility of including distributor 3 and check if by doing so, the overall profitability can be improved.

Table 9. Solution after Iteration

\begin{tabular}{|c|c|c|c|c|}
\hline Distributor & $\begin{array}{c}\text { Constraint } \\
\text { time used }\end{array}$ & $\begin{array}{c}\text { Cumulative } \\
\text { constraint } \\
\text { time used }\end{array}$ & $\begin{array}{c}\text { Constraint } \\
\text { time left }\end{array}$ & $\begin{array}{c}\text { Throughput } \\
(\$)\end{array}$ \\
\hline 1 & 425 & 425 & 2375 & 3100 \\
\hline 4 & 600 & 1025 & 1775 & 3625 \\
\hline 5 & 625 & 1650 & 1150 & 3575 \\
\hline 3 & 825 & 2475 & 325 & 3925 \\
\hline $2 *$ & 375 & & & \\
\hline \multicolumn{5}{|c|}{ Total } \\
\hline
\end{tabular}

* Demand of this distributor cannot be met.

Distributor 3 needs 825 minutes of constraint timing, out of which 775 minutes (unutilized time) are available with department B (constraint). So, it can replace one of those distributors whose constraint time usage is $(825-775=50$ minutes or more and whose throughput is less than that of distributor 3.Constraint time used by all the four distributors i.e. 1,2,4 and 5 are more than 50 minutes and their throughputs are less than that of distributor 3. Among these distributors, throughput of distributor 2 is least. So, let us replace distributor 2 with distributor 3 in the MPS set and put the distributor 3 at the end of the priority list in the MPS set. The improved TOC solution is given in Table 9

Since the throughput of distributor 2 is less than the throughput of distributors $1,3,4$ and 5 . So he cannot replace any other distributor and the solution obtained is final. Demands of the distributors $1,4,5$ and 3 can be fully met. Throughput for this solution comes out to be $\$ 14,225$

The integer linear programming model of the above problem is given below

\section{Objective Function}

$$
\begin{gathered}
\operatorname{Maximize}(Z)=3100 \mathrm{x}_{1}+2675 \mathrm{x}_{2}+3925 \mathrm{x}_{3}+3575 \mathrm{x}_{4}+ \\
3625 \mathrm{x}_{5}
\end{gathered}
$$

Subject to the constraints

$$
\begin{array}{ll}
560 x_{1}+490 x_{2}+645 x_{3}+535 x_{4}+530 x_{5} & \leq 2800 \\
425 x_{1}+375 x_{2}+825 x_{3}+600 x_{4}+625 x_{5} & \leq 2800 \\
440 x_{1}+365 x_{2}+600 x_{3}+560 x_{4}+585 x_{5} & \leq 2800 \\
355 x_{1}+495 x_{2}+710 x_{3}+505 x_{4}+365 x_{5} & \leq 2800 \\
375 x_{1}+350 x_{2}+635 x_{3}+620 x_{4}+620 x_{5} & \leq 2800
\end{array}
$$

where $x_{1}, x_{2}, x_{3}, x_{4}, x_{5}$ are binary variables

The above model was solved by using Integer linear programming method and the results obtained are given in the Table 10 . 
Table 10. Solution Using Integer Linear Programming

\begin{tabular}{|c|c|c|c|c|c|}
\hline Variable & $\mathrm{x}_{1}$ & $\mathrm{x}_{2}$ & $\mathrm{x}_{3}$ & $\mathrm{x}_{4}$ & $\mathrm{x}_{5}$ \\
\hline Value & 1 & 0 & 1 & 1 & 1 \\
\hline
\end{tabular}

Putting these values of $\mathrm{x}_{1}, \mathrm{x}_{2}, \mathrm{x}_{3}, \mathrm{x}_{4}$, and $\mathrm{x}_{5}$ in the objective function, the optimal throughput comes out to be $\$ 14,225$

This value is same as obtained from MTOCh1. Solution of this problem once again proves that MTOh1 is working satisfactorily.

\section{Conclusions and Scope of Further Research}

In this paper, theory of constraint heuristics has been modified to make it applicable to the situations where complete shipment is an additional constraint. The modifications are based on the idea of throughput per customer per constraint minute. The working of the heuristics has been explained by taking two illustrative examples. In both the cases, the proposed heuristics gave the same results as obtained from integer linear programming. This validates the quality of proposed heuristics. Although, this heuristics gives the same solution as we got from integer linear programming. But the additional advantages of using it increase its probability of usage as a management tool. This heuristics will definitely expand the applicability of TOC.

The working of MTOh1 has been tested on two cases only. Further research to test the applicability in different scenarios will further establish the applicability of heuristics proposed. Secondly, this heuristics works in the situations where there is only a single physical constraint, in addition to complete shipment constraint. A real life situation may have multiple physical resource constraints. Further modifications in the proposed heuristics are needed to make it applicable in those situations.

\section{REFERENCES}

[1] Fox R.E., "Theory of Constraints", NAA Conference Proceedings, September, 1987

[2] Fredenall 1. D., Lea B.R., "Improving the product mix heuristics in theory of constraints", International Journal of
Production Research, vol. 35, 1997, pp 1535-1544

[3] Goldratt E. M., Fox R. E., "The Race", North River Press, 1986

[4] Goldratt E. M., "Goal II: It's not luck", North River Press, 1994

[5] Goldratt E. M., "Production The TOC Way", North River Press, 1994

[6] Goldratt E. M., "The Critical Chain”, North River Press, 1997

[7] Goldratt E. M., "What is this thing called Theory of constraints and how should it be implemented", North River Press, 1990

[8] Goldratt E. M., Cox Jeff, "The Goal: A process of ongoing improvements”, North River Press, 1984

[9] Kee R., "Integrating activity based costing with theory of constraints to enhance production related decision making", Accounting Horizons, vol. 9(4), 1995, pp 48-61

[10] Kee Robert, Schmidt Charles, "A comparative analysis of utilizing activity based costing and the theory of constraints for making product mix decisions", International Journal of Production Economics, vol. 63, 2000, pp 1-17

[11] Lea Bih-Ru, Lawrence D. Fredendall, "The impact of Management accounting, product structure, product mix algorithm and planning horizon on manufacturing performance", International Journal of Production Economics, vol. 79 , 2002, pp 279-299

[12] Lee T. N., Plenert G., "Optimized theory of constraints when new product alternatives exist", Production \& Inventory Management Journal, vol. 34(3), 1993, pp 51-57

[13] Luebbe R., Finch B., "Theory of constraints and linear Programming: a comparison", International Journal of Production Research, vol. 30, 1992, pp 1471-1478

[14] Mishra Nihikant, Parkash, Tiwari M. K., Shankar R., Felix T. S. Chan, "Hybrid Tabu- Simulated Annealing based approach to solve multi- constraint product-mix decision problem", Expert Systems with Applications, vol. 29. 2005, pp 446-454

[15] Plenert Gerhard, "Focusing Material requirement planning ( MRP) towards performance", European Journal of Operations Research, vol. 119, 1999, pp 91-99

[16] Plenert Gerhard, "Optimizing theory of constraints when multiple constrained resources exist", European Journal of Operations Research, vol. 70, 1993, pp 126-133

[17] Spoede C., Henke E., Umble M., "Using activity analysis to locate profitability drivers $\mathrm{ABC}$ can support a theory of constraints management process", Management Accounting, vol. 75(11), 1994, pp 43-48 